\title{
A MATHEMATICAL MODEL FOR THE LARGE-SCALE TRANSPORT OF HEAT AND WATER IN THE TAUPO VOLCANIC ZONE OF NEW ZEALAND
}

\author{
GRAHAM WEIR ${ }^{1}$
}

(Received 15 October, 2007; revised 20 January, 2009)

\begin{abstract}
A three-layer compartmental model of the geological structure in the Taupo Volcanic Zone of New Zealand is developed, based on the assumptions of isostasy (constant geostatic pressure at $25 \mathrm{~km}$ depth) and a constant rate of volcanism. The upper layer consists of volcanic infill to a depth of about $2500 \mathrm{~m}$, then a middle layer of greywackelike material to a depth of about $15 \mathrm{~km}$, and a lower layer of andesitic-like material to a depth of $25 \mathrm{~km}$. Our model assumptions predict that the area of each layer increases at a constant rate; that there is a constant ratio between the rate of energy production from volcanic activity and geothermal convection; and that there is the possibility of an abrupt change from rhyolitic to basaltic volcanism, if the middle layer becomes sufficiently thin. Two models are considered: a rifting and a spreading model. Both models predict the lower layer has an andesitic-like density. The spreading model has difficulty matching heat output with observed extension rates. The rifting model predicts the observed extension rates, but requires very deep circulation of groundwater to be consistent with observed chemical and isotopic properties of geothermal fluids.
\end{abstract}

2000 Mathematics subject classification: primary 74C99; secondary 52C35, 74A45.

Keywords and phrases: crustal heat and mass flow, geothermal energy, volcanology.

\section{Introduction}

The Taupo Volcanic Zone (TVZ) lies in the central part of the North Island of New Zealand. The TVZ has been extensively studied, and many of its geophysical and geological properties are known [14, 17]. Both of these references demonstrate that the TVZ is characterized by an intense geothermal heat flow, and very high rates of rhyolitic volcanism.

The location of the TVZ and of its main geothermal fields is shown in Figure 1. The locations of the geothermal fields in Figure 1 have also been calculated from a large-scale numerical model of heat and mass flows in the TVZ region [11], and are in close accord with the actual locations of the TVZ geothermal fields in Figure 1.

\footnotetext{
${ }^{1}$ Applied Mathematics, IRL, Wellington, New Zealand; e-mail: G.weir@irl.cri.nz.

(C) Australian Mathematical Society 2009, Serial-fee code 1446-1811/2009\$16.00
} 
The main concept of that numerical model is that a small percentage of rainwater in the TVZ infiltrates beyond the root zones of vegetation, and it can descend in the central region of the TVZ, away from the boundaries of TVZ, to a depth of up to $8 \mathrm{~km}$. In the model, the rocks heat up to about $350{ }^{\circ} \mathrm{C}$ at these depths, and become ductile, effectively closing off permeability, and so the descending water then begins to move to the boundary of the low-permeability region about the TVZ region, where it rises in distinct plumes to form the geothermal fields.

The relatively long length of around $150 \mathrm{~km}$ of the TVZ in the NE-SW direction, relative to its width of around $30 \mathrm{~km}$ in the NW-SE direction, causes the main descending convection cells in the numerical model to break up into three large convection cells, with each cell having approximately equal lengths and widths. The up-flow regions of these cells correspond to known hot springs and geothermal areas in the central TVZ, the reason for whose location had previously not been explained. While this numerical model of the TVZ geothermal fields has had some success, there remain a number of open questions. The main weakness of that model is that it describes the hydrology only to the base of the convective system at about $8 \mathrm{~km}$ depth, and the heat flows needed to drive the geothermal fields are independent inputs. The main aim of the present paper is to describe a possible model of large-scale heat flow which may be able to address this issue.

We begin by discussing two earlier conceptual models. The first is the rifting model of Wilson et al. [23] which assumes that the greywacke originally occupying the TVZ region has been sheared by deeper extensional forces, into a significantly thinner and wider shape. The second model follows the suggestions of Stern [16] and Weir [20] that the primary heat source for the TVZ geothermal fields results from magma flowing up from about $25 \mathrm{~km}$ depth, to occupy volume created in the crust by extension. The TVZ is known to be extending by at least $8 \pm 4 \mathrm{~mm} \mathrm{yr}^{-1}$ [21] due to motion along known faults. Unfortunately, these rates of extension may be insufficent to describe the known geothermal heat flows from the TVZ, with the model of Stern requiring about $20 \mathrm{~mm} \mathrm{yr}^{-1}$ of extension, and the model of Weir about $13 \mathrm{~mm} \mathrm{yr}^{-1}$ to match volume creation with the observed heat flows. However, 'slow earthquakes' have recently been discovered by GPS measurements in the TVZ [5], in which a plastic-like extension of the crust has been observed over several days. These 'nonseismic' events may possibly add to the known extension rates.

One attempt to explain the observed extension is that it is a transient response during the initiation of the subduction process, associated with plate roll-back [8]. Another idea is that a Rayleigh-Taylor instability could arise from the build-up of dense cooler material under the crust, causing mantle material to break off from under the crust and descend into the asthenosphere, causing extensional stresses in the crust [10]. This mechanism could also provide a source of andesite for TVZ magmas.

This latter mechanism has been considered by $\mathrm{McNabb}$ [12] as the heat source for the TVZ. One attraction of McNabb's model is that it may produce a relatively uniform magma type, as observed across the considerable extent of the TVZ. Yet another 


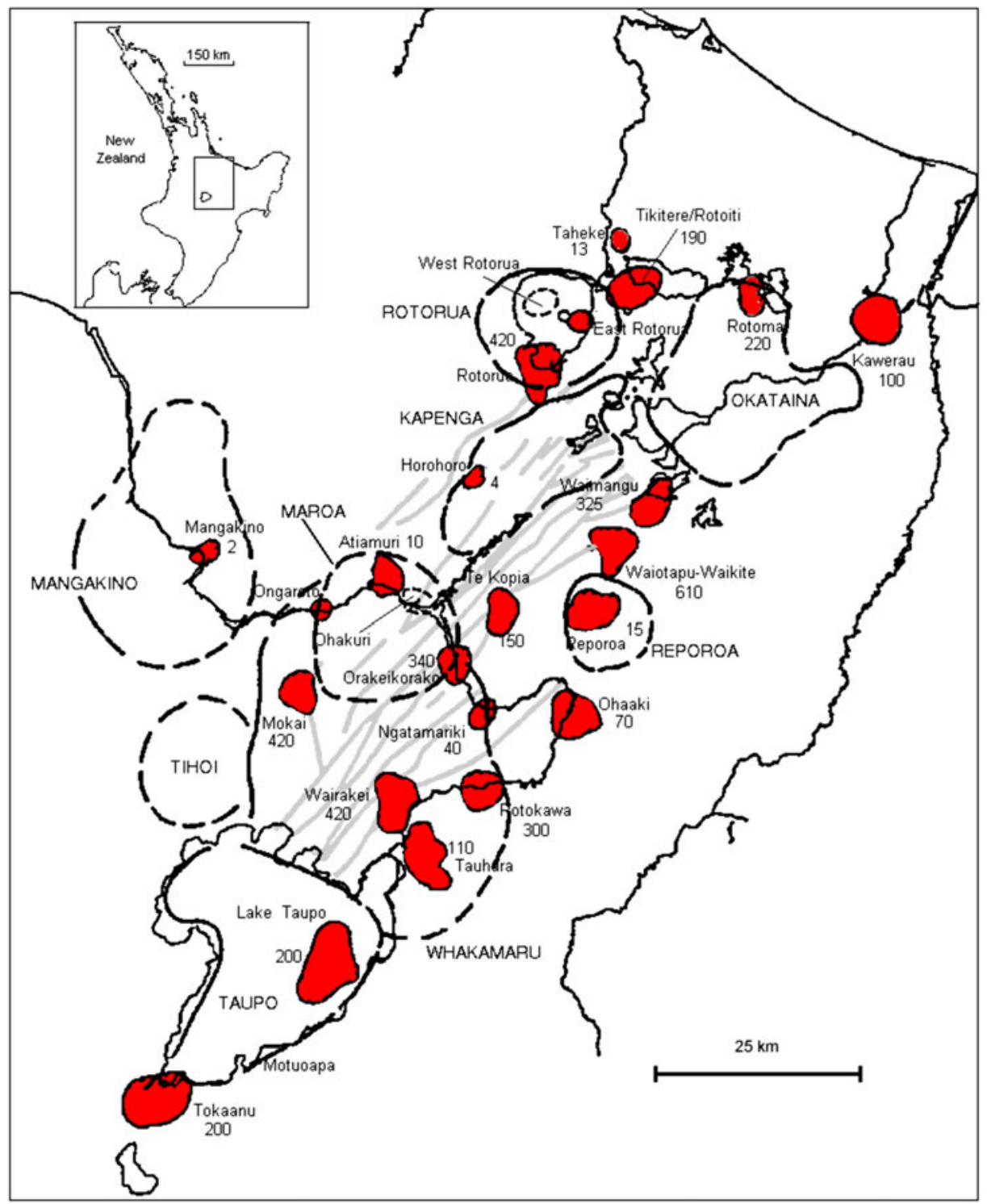

FIGURE 1. Location of the TVZ region of New Zealand. Upper case words relate to known calderas, shown as broken lines. Lower case words relate to known geothermal fields, shown as shaded regions, with the numerals corresponding to heat output in MW. 
alternative is that plastic work [9] could generate large heat flows in the TVZ, similar to processes known to occur in the Tibet region [18].

The great diversity of physical phenomena occurring in the TVZ places severe constraints on any mathematical model, which necessarily needs to be internally selfconsistent. Below we will discuss two simple interdisciplinary models which attempt to capture the main aspects of this heat and fluid flow problem, and to identify the main inferences from these models. The primary aim of this paper is to extend discussion of these earlier models; to comment on the spreading and rifting models for extension in the TVZ; and to consider characteristic times and conditions that may produce a switch from the present rhyolitic to basaltic volcanism.

\section{A three-layer model of the TVZ}

The main aim of this section is to combine the concept of tectonic extension, mentioned above, with that of isostasy. Isostasy implies that pressure is constant at the bottom of the crust, at a depth of about $25 \mathrm{~km}$ [19]. This will occur if the bottom of the crust is liquid-like, with response times that are rapid relative to that for changes in the crust above. Of course, as extension is applied to the crust, this will disturb isostasy, inducing up-flows of magma to restore the pressure distribution at the base of the crust.

Seismic analysis has identified three geological layers under the TVZ [14]. The upper layer of the TVZ consists of pyroclastic infill-material erupted out of volcanoes, and forming a layered structure, with a seismic velocity of about $3 \mathrm{~km} \mathrm{~s}^{-1}$. This layer is known to vary in depth, but here we approximate it having a spatially constant (but time-varying) depth of $z_{1}$. The middle layer, between $z_{1}$ and $z_{2}$, has similarities with greywacke, with a seismic velocity of $5.5-6.1 \mathrm{~km} \mathrm{~s}^{-1}$. Currently $z_{2}$ is thought to be at about $15 \mathrm{~km}$ depth. Some researchers [23] have suggested this layer is indeed greywacke, whereas others [7] suggest the presence of magmatic materials, in order to produce the characteristic chemical and isotopic signatures of the TVZ geothermal fluids [6]. If groundwater can circulate down to $15 \mathrm{~km} \mathrm{depth}$, then the middle layer could be mostly greywacke, but if not, then it seems likely that magmatic material will need to have risen higher, in order to make contact with groundwater. The lower layer has a seismic velocity of $7.4-7.5 \mathrm{~km} \mathrm{~s}^{-1}$, which is close to the seismic velocity of $7.6 \mathrm{~km} \mathrm{~s}^{-1}$ for mantle material adjacent to the TVZ, suggesting that basaltic-like material has risen up below the TVZ to form the lower layer [1].

Presumably, 1.6 million years ago, just as the TVZ was beginning to form, the upper and lower layers were absent, and the immediate problem is to generate simple mathematical models which describe the development of the depth structure and width of the TVZ, and predict its future evolution. We shall proceed by considering two models: the rifting and spreading models.

2.1. Rifting model The rifting model was introduced by Wilson [23], who assumed that the middle layer is composed of greywacke, and that the volume and density of the middle layer remain spatially and temporally constant, but that its depth reduces 
and its width increases with time. We assume, in addition, that the density of the different layers has remained constant over time. The assumption of isostasy implies that the pressure at the original depth ( $z_{3}$ equalling $25 \mathrm{~km}$ ) of the crust remains constant with time,

$$
\rho_{1} z_{1}+\rho_{2}\left(z_{2}-z_{1}\right)+\rho_{3}\left(z_{3}-z_{2}\right)=\rho_{2} z_{3},
$$

and so there is a linear relationship between the three layer depths,

$$
\left(\rho_{2}-\rho_{1}\right) z_{1}=\left(\rho_{3}-\rho_{2}\right)\left(z_{3}-z_{2}\right)
$$

or

$$
\left(\rho_{2}-\rho_{1}\right) z_{3}=\left(\rho_{2}-\rho_{1}\right)\left(z_{2}-z_{1}\right)+\left(\rho_{3}-\rho_{1}\right)\left(z_{3}-z_{2}\right) .
$$

We assume that the density of the layers increases with depth, $\rho_{1}<\rho_{2}<\rho_{3}$, and so the bracketed terms involving density in (2.1)-(2.3) are positive. Volcanism will increase $z_{1}$ over time, and so from (2.2), the lower layer also increases in thickness with time, and so the middle layer decreases in thickness over time, because the total thickness $z_{3}$ remains fixed. Equations (2.2) and (2.3) predict that all of the layer thicknesses are linearly related.

Implicit in (2.3) is the critical thickness $z_{1}^{c}$ of the upper layer, corresponding to the disappearance of the middle layer,

$$
\frac{z_{1}^{c}}{z_{3}}=\frac{\rho_{3}-\rho_{2}}{\rho_{3}-\rho_{1}} .
$$

If the degree of volcanism is sufficiently great to effectively destroy the middle layer, then the conceptual model in this paper will break down once the critical condition in (2.4) holds, and we expect that some significant change will occur in the corresponding physical system.

The current stage of rhyolitic volcanism in the TVZ began 1.6 million years ago [1]. Over this period, the width $w$ of the TVZ has increased, due to the local extensional tectonic regime [1]. If $w_{0}$ is the initial width of the greywacke layer, about to be rifted, then because we are assuming here that the cross-sectional area of the middle layer remains constant,

$$
w_{0} z_{3}=w\left(z_{2}-z_{1}\right)
$$

and so from (2.1)-(2.3) the cross-sectional areas of the upper and lower layers satisfy

$$
\begin{array}{r}
w z_{1}=\frac{\left(\rho_{3}-\rho_{2}\right) z_{3}}{\left(\rho_{3}-\rho_{1}\right)}\left(w-w_{0}\right), \\
w\left(z_{3}-z_{2}\right)=\frac{\left(\rho_{2}-\rho_{1}\right) z_{3}}{\left(\rho_{3}-\rho_{1}\right)}\left(w-w_{0}\right) .
\end{array}
$$

If the area of the upper layer $w z_{1}$ is to increase at a constant rate, as suggested by the almost constant rate of eruption in the TVZ [21], then from (2.6),

$$
w-w_{0}=R t
$$


and so the extension rate $R$ must be constant, and also from (2.7), the lower layer also increases its area $w\left(z_{3}-z_{2}\right)$ at a constant rate.

The rifting model does not identify clearly the heat flows associated with rifting. However, if we assume that as magma moves from the base to the top of the lower layer, where it is cooled by deeply circulating groundwater, then a temperature difference of $\Delta T_{3}$ can be imagined to occur across the rising magma, and this heat flow could then drive the TVZ geothermal fields. The corresponding energy flow $\dot{E}$ from (2.7) and (2.8) is

$$
\dot{E}=\rho_{3} l C \Delta T_{3} \frac{d\left[w\left(z_{3}-z_{2}\right)\right]}{d t}=\rho_{3} l C \Delta T_{3} \frac{\left(\rho_{2}-\rho_{1}\right) z_{3}}{\left(\rho_{3}-\rho_{1}\right)} R .
$$

Here $l$ is the length of the TVZ, about $160 \mathrm{~km}$, and $C$ is the specific heat of the rock. Note that for this to be a viable mechanism, groundwater would need to circulate down to the top of the lower layer, which at the beginning of the TVZ was at $25 \mathrm{~km}$ depth. This is much greater than has been assumed previously, but may be possible, provided the rock remains cool enough to be permeable to water.

2.2. Spreading model The spreading model [16, 20] also assumes a three-layer structure, but the area (volume) of the middle layer needs to increase to accept material intruded into its structure. Large magnetic anomalies in the TVZ [15] suggest that large amounts of magma have been emplaced into the middle layer. We continue to assume constant layer densities, although this assumption is probably violated somewhat in the middle layer, due to emplacement of intrusives.

We now assume that area (volume per unit length) is generated in both the upper and middle layers at constant rates, $\dot{A}_{1}$ and $\dot{A}_{2}$ respectively, in order to obtain constant rates of volcanism and geothermal energy flux from the TVZ. Then

$$
w z_{1}=\dot{A}_{1} t, \quad w\left(z_{2}-z_{1}\right)-w_{0}^{s} z_{3}=\dot{A}_{2} t,
$$

where $w_{0}^{s}$ is the initial width of the TVZ in the spreading model, and from (2.2),

$$
w\left(z_{3}-z_{2}\right)=\frac{\left(\rho_{2}-\rho_{1}\right) \dot{A}_{1} t}{\left(\rho_{3}-\rho_{2}\right)}
$$

and so all areas have a constant rate of change.

Adding the terms on the left of (2.10) and (2.11) gives

$$
\left(w-w_{0}^{s}\right) z_{3}=\left(\dot{A}_{2}+\frac{\left(\rho_{3}-\rho_{1}\right) \dot{A}_{1}}{\rho_{3}-\rho_{2}}\right) t=R_{s} z_{3} t,
$$

and comparing (2.12) with (2.8) gives the extension rate $R_{S}$ in the spreading model. Then substituting this result into (2.10) gives

$$
z_{2}-z_{1}=\frac{w_{0}^{s} z_{3}+\dot{A}_{2} t}{w_{0}^{s}+R_{s} t} \Longrightarrow \lim _{t \rightarrow \infty}\left(z_{2}-z_{1}\right)=\frac{\dot{A}_{2}}{R_{s}}
$$


and so the thickness of the middle layer tends over time to a nonzero asymptotic value $\left(\dot{A}_{2} / R_{s}\right)$, independent of $w_{0}^{s}$. Hence so does the thickness of the upper and lower layers,

$$
z_{1}=\frac{\dot{A}_{1} t}{w_{0}^{s}+R_{s} t} \Longrightarrow \lim _{t \rightarrow \infty} z_{1}=\frac{\dot{A}_{1}}{R_{s}}
$$

and therefore

$$
z_{3}-z_{2}=\frac{\left(\rho_{2}-\rho_{1}\right) \dot{A}_{1} t}{\left(\rho_{3}-\rho_{2}\right)\left(w_{0}^{s}+R_{s} t\right)} \Longrightarrow \lim _{t \rightarrow \infty}\left(z_{3}-z_{2}\right)=\frac{\left(\rho_{2}-\rho_{1}\right) \dot{A}_{1}}{\left(\rho_{3}-\rho_{2}\right) R_{s}}
$$

It does not seem possible to determine the magnitude of $\dot{A}_{2}$ easily from these expressions. However, since $w_{0}^{s}$ will always be nonnegative, we have from (2.12) and (2.10) that

$$
\dot{A}_{2} \leq \dot{A}_{1}\left(\frac{z_{3}}{z_{1}}-\frac{\rho_{3}-\rho_{1}}{\rho_{3}-\rho_{2}}\right) .
$$

The fraction of intrusives, $f_{I}$, in the middle layer is then

$$
f_{I}=\frac{\dot{A}_{2} t}{w\left(z_{2}-z_{1}\right)}
$$

and, from (2.10), this tends to unity for large time. As an example, if the middle layer is one half full of intrusives at the present time, then $\dot{A}_{2}$ would be about one half of the maximum value given in Table 1 , that is,

$$
\dot{A}_{2}=\frac{0.5 \times 30 \times 10^{3} \times 12.5 \times 10^{3}}{1.6 \times 10^{6} \times 3 \times 10^{7}} \simeq 4 \times 10^{-6} \mathrm{~m}^{2} \mathrm{~s}^{-1} .
$$

The heat flow implied in the spreading model results from the intruded volume of material into the middle layer, where groundwater transports the heat into the TVZ geothermal fields.

The corresponding energy flow $\dot{E}$ is

$$
\dot{E}=\rho_{2} l C \Delta T_{2} \frac{d\left[w\left(z_{2}-z_{1}\right)\right]}{d t}=\rho_{2} l C \Delta T_{2} \dot{A}_{2},
$$

where (2.10) has been used, and $\Delta T_{2}$ is the change in temperature produced by groundwater contacting the intruded magma.

\section{Parameter selection}

Geophysical measurements fix many of the parameters in these models, and we provide estimates of these in Table 1. Seismic measurements [1] suggest that the present values of $z_{1}, z_{2}$ and $z_{3}$ are $2.5 \mathrm{~km}, 15 \mathrm{~km}$, and $25 \mathrm{~km}$, respectively. Assuming that the middle layer has the density of greywacke [4, Figure 13], and the density of the upper layer is $2170 \mathrm{~kg} \mathrm{~m}^{-3}$ [13], gives the lower layer an average density 
TABLE 1. Parameter values assumed in this paper.

\begin{tabular}{llll}
\hline & Definition & Value & Ref. \\
\hline$\dot{A}_{1}$ & Rate of increase of upper layer area & $1.5 \times 10^{-6} \mathrm{~m}^{2} \mathrm{~s}^{-1}$ & $(2.10)$ \\
$\dot{A}_{2}$ & Rate of increase of middle layer area & $\leq 8 \times 10^{-6} \mathrm{~m}^{2} \mathrm{~s}^{-1}$ & $(2.10)$ \\
$C$ & Specific heat of magma & $1300 \mathrm{~J} \mathrm{~kg}^{-1} \mathrm{~K}^{-1}$ & {$[2]$} \\
$\dot{E}$ & TVZ geothermal energy flow & $4200 \mathrm{MW}$ & {$[1]$} \\
$l$ & Length of TVZ & $160 \mathrm{~km}$ & {$[21]$} \\
$R$ & Extension rate for rifting model & $9 \mathrm{~mm} \mathrm{yr}$ & $(2.8)$ \\
$R_{s}$ & Extension rate for spreading model & $\leq 19 \mathrm{~mm} \mathrm{yr}$ & $(2.12)$ \\
$w$ & Width of TVZ & Variable $(30 \mathrm{~km})$ & {$[21]$} \\
$w_{0}$ & Initial width for rifting model & $15 \mathrm{~km}^{-1}$ & $(2.8)$ \\
$w_{0}^{s}$ & Initial width for spreading model & Nonnegative & $(2.12)$ \\
$z_{1}$ & Depth of the upper layer & Variable $(2.5 \mathrm{~km})$ & {$[1]$} \\
$z_{1}^{c}$ & $z_{1}$ where the middle layer disappears & $5 \mathrm{~km}$ & $(2.4)$ \\
$z_{2}$ & Lower depth of the middle layer & Variable $(15 \mathrm{~km})$ & {$[1]$} \\
$z_{3}$ & Lower depth of the lower layer & $25 \mathrm{~km}^{\circ}$ & {$[1]$} \\
$\Delta T_{2}$ & Middle layer magma temperature drop & $400-800^{\circ} \mathrm{C}$ & - \\
$\Delta T_{3}$ & Lower layer magma temperature drop & $400-800{ }^{\circ} \mathrm{C}$ & - \\
$\rho_{1}$ & Density of the upper layer & $2170 \mathrm{~kg} \mathrm{~m}^{-3}$ & {$[13]$} \\
$\rho_{2}$ & Density of the middle layer & $2670 \mathrm{~kg} \mathrm{~m}^{-3}$ & {$[4]$} \\
$\rho_{3}$ & Density of the lower layer & $2795 \mathrm{~kg} \mathrm{~m}^{-3}$ & $(2.1)$ \\
\hline
\end{tabular}

of $2795 \mathrm{~kg} \mathrm{~m}^{-3}$, using (2.1). If we imagine that the lower layer has been formed from an inflow of basalt, then our calculated lower layer density is quite low relative to that of basalt, which could have a density of about $3300 \mathrm{~kg} \mathrm{~m}^{-3}$. However, the composition of material at the base of the TVZ remains a controversial topic, with Cole [3] suggesting that this region is occupied mostly by andesite. Typically andesite has a density of $2500-2800 \mathrm{~kg} \mathrm{~m}^{-3}$, consistent with the value of $2795 \mathrm{~kg} \mathrm{~m}^{-3}$ derived for the density of the lower layer from (2.2).

The right-hand side of (2.4) is 0.2 , and so the critical depth implied for the upper layer is $5 \mathrm{~km}(=25 \mathrm{~km} / 5)$. Thus if extensional processes continue in the TVZ, and double the present thickness of the upper layer, then we would expect that the thickness of the middle layer would have then reduced to a negligible value, and this could produce a distinct change in the nature of volcanism in the TVZ.

Estimates for the initial width of the TVZ are model-dependent. For the rifting model, $w_{0}$ is fixed from (2.5) at half its present value $\left(w_{0} / w=12.5 \mathrm{~km} / 30 \mathrm{~km}\right)$. The present width of the TVZ is about $30 \mathrm{~km}$, making the initial width about $15 \mathrm{~km}$ for the rifting model. Then from (2.8), the value of the extension rate for the TVZ is $15 \mathrm{~km} /(1.6 \mathrm{Myr})=9 \mathrm{~mm} \mathrm{yr}^{-1}$, which is consistent with the geodetic and GPS 
measurements of $8 \pm 4 \mathrm{~mm} \mathrm{yr}^{-1}$ [20]. From (2.9), the rate of energy production from the rifting model is then $2200-4400 \mathrm{MW}$, which is marginally consistent with the present heat flow of $4200 \mathrm{MW} \pm 400 \mathrm{MW}$ [1] from the TVZ. The assumed temperature drops of $400-800{ }^{\circ} \mathrm{C}$ for $\Delta T_{2}$ and $\Delta T_{3}$ in Table 1 followed from assuming initial magma temperatures of between $800-1200{ }^{\circ} \mathrm{C}$ and a final temperature for brittle rock of $400{ }^{\circ} \mathrm{C}$.

For the spreading model, the rate of increase $\dot{A}_{1}$ of the thickness of the upper layer is calculated from $(2.10)$ at about $1.6 \times 10^{-6} \mathrm{~m}^{2} \mathrm{~s}^{-1}$. Unlike the rifting model, it is not possible to proceed beyond here without additional assumptions. We will proceed by obtaining upper bound estimates for $\dot{A}_{2}$ and $\dot{E}$, by setting either $w_{0}$ to zero in (2.10), or equivalently using (2.13), both of which imply that $\dot{A}_{2} \leq 5 \dot{A}_{1}$. Then from (2.10), $\dot{A}_{2}$ has an upper bound of $8 \times 10^{-6} \mathrm{~m}^{2} \mathrm{~s}^{-1}$, and from (2.14), $\dot{E}$ is bounded above by about 1700-3400 MW (depending on the choice of $\Delta T_{2}$ ), which is lower than the presently measured energy output from the TVZ of $4200 \pm 400 \mathrm{MW}$ [1]. This upper bound corresponds to an extension rate of $19 \mathrm{~mm} \mathrm{yr}^{-1}$ (that is, $30 \mathrm{~km} / 1.6 \mathrm{Myr}$ ), which is much greater than is currently observed, and so the actual heat output from a spreading model will need to be smaller than these upper bounds.

\section{Discussion and conclusions}

The estimates of around 2000-4000 MW for heat output from the rifting and spreading models of the TVZ are consistent with previous models. However, it is likely [21] that conduction may add another $1000 \mathrm{MW}$, and transient fluid flows may also add another $1000 \mathrm{MW}$, so that the total heat flow will approach the known output of $4200 \mathrm{MW}$ [1] of the TVZ. However, it needs to be emphasized that the rifting and spreading models still contain several significant unanswered questions.

The major problem with the rifting model is the ability of the groundwater to reach the bottom of the crust. In particular, groundwater will need to travel to $25 \mathrm{~km}$ depth at the beginning of the TVZ, around 1.6 million years ago, if this model is to be valid. Without this, the chemicals and isotopes from the magma will not be absorbed into the descending groundwater, to give its observed geothermal signature. The usual temperature gradient from heat conduction is around $30^{\circ} \mathrm{C}$ per $\mathrm{km}$, so at $25 \mathrm{~km}$ we expect to encounter $750^{\circ} \mathrm{C}$. This is well above the brittle-ductile transition temperature of rock, and so steady permeability should reduce significantly at such depths, and groundwater would not reach $25 \mathrm{~km}$ under these conditions. However, it is possible that the descending groundwater could cool the rock sufficiently to keep the temperature below the brittle-ductile transition temperature (say, below $400{ }^{\circ} \mathrm{C}$ [1]), to maintain permeability and so allow groundwater access to great depths. A recent paper [22] shows that this mechanism is possible.

At the sites of the geothermal fields it is difficult to imagine groundwater penetrating much below $8 \mathrm{~km}$ (given the geophysical gradient in temperature), and so if we are considering groundwater penetrating to $25 \mathrm{~km}$ in the interior of the TVZ, then there must be quite steep isotherms about the boundaries of the TVZ, where groundwater 
rises from $25 \mathrm{~km}$ or so, up to above $8 \mathrm{~km}$ in the region of the geothermal fields. In this case, the geological structure may determine the depth of penetration of groundwater in the central regions of the TVZ, but thermal effects may control its depth around the boundaries, especially about the sites of the geothermal fields.

Another unanswered question concerns the nature of the magmatic source fuelling the TVZ. While most of the erupted magmas from the TVZ are rhyolitic (high in silica content), they are believed [3] to be of a largely andesitic origin, and not to be contaminated significantly with greywacke [7]. The latter point seems to be in contradiction with the spreading model, in which there should be intimate contact between the greywacke and the intruding magmas. Conversely, the rifting model would allow the presence of a lower andesitic source magma. Furthermore, the density calculated for the lower layer in this model is consistent with the density for an andesitic source, but not for a basaltic source. If we accept that the deeper magma source is andesitic, then the upper bounds for $\Delta T_{2}$ and $\Delta T_{3}$ of $800^{\circ} \mathrm{C}$ seem plausible, given an andesitic temperature of $1200{ }^{\circ} \mathrm{C}$, and a circulating water temperature of no more than $400{ }^{\circ} \mathrm{C}$.

Another constraint on these two models is the rate of extension needed to generate the observed heat flow. The rifting model has the advantage of predicting correctly the present observed rates of extension in the TVZ, using the independent information of the present layer thicknesses and the known age of the TVZ, that is, the tectonic extension rate is not an input - but an output - in the rifting model. Specifically, for the rifting model,

$$
R=\frac{w\left(z_{3}+z_{1}-z_{2}\right)}{z_{3} t}
$$

and all of the terms on the right-hand side of (4.1) are known. In contrast, the spreading model does not independently predict the extension rate, but this is left free, together with the model heat flow. However, strict upper bounds on these variables hold when the initial width of the TVZ is set to zero.

The spreading model has difficulty in generating sufficient volume to accommodate the observed heat flow. Specifically, the growth of the upper and lower layers reduces the thickness of the middle layer, and so the requirement to intrude magma into the volume created in the middle layer implies increased extension rates, to overcome the reduction of thickness of the middle layer. This is presumably the main reason why spreading models require extension rates which seem unreasonably high, and provides an argument against such models.

The possibility arises that significant changes in magma type may occur if the thickness of the middle layer reduces sufficiently. If we assume that a magma chamber in the middle layer is needed to incubate and fractionate the andesitic magma source into a rhyolitic magma, then it seems likely that some minimum thickness of the middle layer will be needed to produce rhyolitic magmas. Consider, for example, $20 \%$ of the average magma flow in the TVZ to be directed into one magma chamber, for (say) $10000 \mathrm{yrs}$. The total flow of magma into the TVZ [24] is believed to be about $1.5 \mathrm{~m}^{3} \mathrm{~s}^{-1}$, and implies a flow of $0.3 \mathrm{~m}^{3} \mathrm{~s}^{-1}$ into the chamber, eventually producing 
about $100 \mathrm{~km}^{3}$ of magma. This volume would occupy $6 \mathrm{~km}$ by $6 \mathrm{~km}$ horizontally, and $3 \mathrm{~km}$ vertically. Hence we obtain an estimate for the minimum thickness of the middle layer to be around $3 \mathrm{~km}$. This corresponds in a rifting model to a final width of $125 \mathrm{~km}$, which occurs about 10 million years after the beginning of the TVZ. It is not possible to discuss timing issues in the spreading model in the same detail as the rifting model, because of the unknown value of $\dot{A}_{2}$.

Finally, we comment that another difference between the rifting and spreading models is that the middle layer in rifting models tends to zero over time, and thus will always eventually destroy any magma chamber in the middle layer. However, in the spreading model, the middle layer always tends to a nonzero asymptotic value which offers the possibility of long-term rhyolitic volcanism for these models.

\section{Acknowledgements}

This paper is dedicated to the memory of Dr Stephen White. The author thanks Warwick Kissling for Figure 1, and Robert McKibbin for a careful review.

\section{References}

[1] H. M. Bibby, T. G. Caldwell, F. J. Davey and T. H. Webb, "Geophysical evidence on the structure of the Taupo Volcanic Zone, and its hydrothermal circulation”, J. Volcanol. Geotherm. Res. 68 (1995) 29-58.

[2] C. Clauser and E. Huenges, "Thermal conductivity of rocks and minerals", in: Rock physics and phase relations, A Handbook of Physical Constants, AGU Reference Shelf 3 (ed. T. J. Ahrens), (American Geophysical Union, Washington, DC, 1995) (http://www.agu.org/reference/rock. html).

[3] J. W. Cole, "Structural control and origin of volcanism in the Taupo Volcanic Zone, New Zealand", Bull. Volcanol. 52 (1990) 445-459.

[4] F. J. Davey, S. A. Henrys and E. Lobolo, "Asymmetrical rifting in a continental backarc environment, North Island, New Zealand”, J. Volcanol. Geotherm. Res. 68 (1995) 209-238.

[5] E. Delahaye, J. Townend, M. Reyners and G. Rogers, "Microseismicity but no tremor associated with slow slip in the Hikurangi subduction zone, New Zealand", Earth Planet. Sci. Lett. 277 (2009) 21-28.

[6] W. F. Giggenbach, "Isotopic shift in waters from geothermal and volcanic systems along convergent plate boundaries and their origin", Earth Planet. Sci. Lett. 113 (1992) 495-510.

[7] I. J. Graham, J. W. Cole, R. M. Briggs, J. A. Gamble and I. E. M. Smith, "Petrology and petrogenesis of volcanic rocks from the Taupo Volcanic Zone: a review", J. Volcanol. Geotherm. Res. 68 (1995) 59-87.

[8] C. E. Hall, "Catastrophic initiation of subduction following forced convergence across fracture zones”, Earth Planet. Sci. Lett. 212 (2003) 15-30.

[9] M. P. Hochstein, "Crustal heat transfer in the Taupo Volcanic Zone (New Zealand): comparison with other volcanic arcs and explanatory heat source models", J. Volcanol. Geotherm. Res. 68 (1995) 117-151.

[10] G. Housemann and P. Molnar, "Gravitational (Rayleigh-Taylor) instability of a layer with nonlinear viscosity and convective thinning of continental lithosphere", Geophys. J. Int. 128 (1997) $125-150$.

[11] W. M. Kissling and G. J. Weir, "The spatial distribution of the geothermal fields in the Taupo Volcanic Zone, New Zealand”, J. Geophys. Res. 145 (2005) 136-150. 
[12] A. McNabb, "The Taupo-Rotorua Hot-Plate", Proc. 14th New Zealand Geothermal Workshop (eds S. F. Simmons, J. Newson and K. C. Lee), (Geothermal Institute, University of Auckland, Auckland, 1992) 111-114.

[13] N. Modrinak and F. E. Studt, "Geological structure and volcanism of the Taupo-Tarawera District", N.Z. J. Geol. Geophys. 2 (1959) 654-684.

[14] S. F. Simmons and S. D. Weaver (eds), "Taupo Volcanic Zone, New Zealand", J. Volcanol. Geotherm. Res. 68 (1995) 1-238.

[15] S. Soengkono, 'A magnetic model for deep plutonic bodies beneath the central Taupo Volcanic Zone, North Island, New Zealand', J. Volcanol. Geotherm. Res. 68 (1995) 193-207.

[16] T. A. Stern, "Asymmetrical back-arc spreading, heat flux and structure associated with the central volcanic region of New Zealand", Earth Planet. Lett. 85 (1987) 265-276.

[17] T. A. Stern, W. R. Stratford and M. L. Salmon, "Subduction evolution and mantle dynamics at a continental margin: Central North Island, New Zealand", Rev. Geophys. 44 (2006) RG4002RG4038.

[18] P. Tapponnier and P. Molnar, "Slip line field theory and large-scale continental tectonics", Nature 264 (1976) 319-324.

[19] A. B. Watts, Isostasy and flexure of the lithosphere (Cambridge University Press, Cambridge, 2001).

[20] G. J. Weir, "Transport processes in the Taupo Volcanic Zone, New Zealand", J. Volcanol. Geotherm. Res. 84 (1998) 61-72.

[21] G. J. Weir, "Heat output from spreading and rifting models of the Taupo Volcanic Zone, New Zealand", J. Appl. Math. Decis. Sci. 5(1) (2001) 119-132.

[22] G. J. Weir, "A mathematical model of rainfall-controlled geothermal fields", Transp. Porous Media 77 (2009) 323-334.

[23] C. J. N. Wilson, B. F. Houghton, M. O. McWillaims, M. A. Lanphere, S. D. Weaver and R. M. Briggs, "Volcanic and structural evolution of Taupo Volcanic Zone, New Zealand: a review", J. Volcanol. Geotherm. Res. 68 (1995) 1-28.

[24] C. J. N. Wilson, A. M. Rogan, I. E. M. Smith, D. J. Northey, I. A. Nairn and B. F. Houghton, "Caldera volcanoes of the Taupo Volcanic Zone, New Zealand", J. Geophys. Res. 89 (1984) 8463-8484. 